\title{
APUNTES PARA UNA LECTURA DE LA POESÍA URUGUAYA CONTEMPORÁNEA
}

\author{
POR \\ CARLOS PELLEGRINO \\ Universidad de la República, Montevideo
}

Inicialmente estas consideraciones sólo pretendieron dar cuenta de la geografía de mis lecturas, aunque luego quisieron recomponerse a la luz de una posible lectura sincrónica del paisaje literario, y en él, del espacio poético y aún menos, de unos cuantos autores y algunas de sus obras. Luego todo se complicó. Ello no alcanza, ni en mucho, para acercarse a un balance de la producción poética en el Uruguay de las últimas décadas, pero quizás permita arriesgar ciertos parentescos e interinfluencias que buscan el subsuelo de lo que en cada obra resuena separadamente.

Es sorprendente advertir las distancias que dicha producción guarda con el contexto mayor al que aparece intermitentemente ligada (¿el Río de la Plata, la zona cultural sur-atlántica o región transplatina austral?); sobre todo si se tiene en cuenta que lo que intramuros no alcanza explicación satisfactoria, recupera nitidez si se atiende al paralelo de lo sucedido en los grandes escenarios de la región (en especial en las grandes ciudades capitales).

Debo decir, antes que otra cosa, que dado que no soy un scholar literario o un crítico, me siento confortablemente instalado en la condición de discutible outsider a la que, por otras circunstancias de mi vida, he aprendido a amar como propia. El hecho, por otra parte, de que yo mismo sea autor de varios libros de poemas, que haya debido encargarme de la dirección de la Revista Maldoror durante más de diez números -lo que significa una obligación de lector de segundo grado-, y seguido atento a las notas, reseñas y antologías que se publicaron, me hace partícipe más en una tarea de agitación y propuesta que en otras imbuidas de trascendencia final.

Quizá, la originalidad de nuestro patrimonio cultural y su silenciosa densidad corren parejas con cierta forma de atonía e indiferencia en participar de la peripecia del continente, que, como Real de Azúa propusiera, "fue construido sobre el espacio y no sobre el tiempo". Raúl Antelo ha estudiado notablemente la idea -en la Argentina de Mármol y Alberdi- de la Nación como desierto, ese espacio sin tiempo, para acercarlo a la necesidad de darle "más de un tiempo" al tiempo de la escritura en el contexto de una revisión del concepto de literaturas nacionales. Haroldo de Campos en un libro fundamen- 
tal: "El Secuestro del barroco en la formación de la literatura brasileña: el caso Gregorio de Matos”, se refiere a la encarnación literaria del espíritu nacional, la cuestión del origen, la historia integrada y la tradición continua de dicha literatura. También en nuestro caso deberíamos ensayar una explicación no monológica, de carácter inconcluso abierto y anticipatorio. También partimos, como estudia Antelo, de un vacío y una necesidad de tiempo estratificado para cobijar un ámbito no-reductor que no sea excluyente de lo extraño, en el espacio de la literatura nacional del Uruguay. Sería dificil discernir en el conjunto de las obras que intentan conformar la copa integral de la literatura nacional, el advenimiento inequívoco de un empeño coherente y orgánico. No hay cifras que nos impongan la nostalgia de tiempos cíclicos. Debe, creo yo, señalarse que durante el período de climax de la generación del 45 , se hizo posible un amplio discurrir entre generaciones y sus discursos paralelos pero, si se respiró tal atmósfera vinculante, fue como consecuencia del esfuerzo de dicha generación por revisar cimientos y afinidades. Aun señalando vicisitudes estéticas, obras diversas de excelencia y áreas plurales de ejercicio creativo, el espacio de la producción poética desde 1965 - por establecer una fecharelativamente plausible para la transición y el relevo con la generación del 45- intenta delinear su presencia en la difícil claridad de estructuras poco nítidas. Por otra parte, no pocas figuras y obras deslumbrantes han zigzagueado entre grupos y períodos, sin dejarse apresar por fronteras o cancelaciones que permitan la aplicación sencilla de modelos explicativos. Se asiste a la boga de grupos más que a la conquista de un futuro activado internamente; a deslizamientos graduales más que a rupturas apoyadas en valores contrastantes a los de otros grupos o generaciones anteriores; a una variedad de registros y tonalidades que se acercan o se alejan sin beligerancia o sobresaltos de originalidad.

Esta zona cultural sur-atlántica, más que otras, por la condición de sus sociedades aluvionales, demuestra hasta qué punto la historia de América Latina ha sido la construcción de una utopía y la formulación de respuestas creativas a los impactos europeos a través de procedimientos transculturales y formas de apropiación y decantación que resemantizan influencias y sus modelos. "Nuestro grande e involuntario revoltijo de sangres y culturas" irrumpe polifónicamente a través de siglos de "historia esotérica e historia visible ${ }^{n}$, diseminando de manera epifánica su excentricidad y transgresión dialógica. De Martí y Rubén Darío a Borges y Huidobro, de Gregorio de Matos y Lezama Lima a Oliverio Girondo y Haroldo de Campos, de Juan José Tablada y Octavio Paz a Neruda y Nicanor Parra. De Lautréamont a Vallejo.

La poesía ha acompañado la evolución de la República y sus precisos remordimientos de ser país (de territorio exiguo). El paisaje de los poetas revolucionarios estuvo ensangrentado por pasiones elementales, "fratricidios espirituales" y la frustración de una ciudad que condena al impulso exigiéndole tirarse al río. La primera obra poética de la que conserva referencia, según Francisco de Bauzá (Estudios Literarios, 1885) es un drama en verso, debe ser re-presentado: "La virtud más acendrada y de Buenos Aires vengada" de Juan Francisco Martínez, capellán militar. 
Si rechazamos el enfoque linear de la historia de la poesía uruguaya que se ha querido incrustar en una visión ontológico-nacionalista de su tradición, debemos considerar a los Cantos de Maldoror y a Lautréamont como su padre fundador. ¿Cómo podía no ser un extranjero el poeta que por su 'hybris' descomunal destilara el poder surreal? Extranjero a todo poder. Más aún en un país geográficamente intermediario entre territorios de pasión natural bien diferenciada. Advertencia de la costa para divisar otra escena. El lugar de la escena original estará soterrado amortiguadamente aclimatando lo que pueda considerarse cimentado en un imaginario propio. Lautréamont ha desencadenado una novedad absoluta rodeado de aleaciones barrocas y nuestra pertenencia al mundo. Nuestro origen transcriado-oceánico.

El acto matricial de la historia de la poesía en el Río de la Plata, es ese bautismo traumático maldororiano: la salvación por el viaje a la profundidad. Algo semejante al infierno y al gesto de la pérdida pero también a la emergencia de un rito de elocuencia y redención.

La dinámica del discurso crítico es de una incidencia radical sobre la evolución y el progreso de un paisaje poético, para impulsar el cambio del horizonte de recepción de las obras. La generación del 45 , más predestinada que ninguna otra a encarnar la condición nacional como fruto de una conciencia desdichada, mantuvo sus acordes críticos y un contrapunto de oposiciones, conjunciones y disyunciones apasionadas alternando con la producción. Las generaciones que le siguen carecen antes que nada de una recepción sustanciosa. Ello se agravó en el período posterior a 1974. Escamotear la responsabilidad que cada generación debe asumir en la revisión de afinidades y valores equivale a la suspensión de garantías de elección y a paseos por playas paralelas. Tal parece lo que sucedió. Entre faltas de omisión y decomisos de lectura, la crítica (oficiante como tal) desdeñó la tarea de mantener un espacio plural de resonancia de las obras o se reservó el derecho a una indiferencia selectiva (quizá deliberada, quizá fruto del que podría denominarse efecto del "cielito nublado"). Las poderosas razones de la al dea convencieron a ciertos críticos que omitir y desleer era significativo. Lograron así un acorde cultural dominante, que paradojalmente resultó un acuerdo por descarte. Existen además suficientes premios municipales per-capita en relación al número de poetas ( $\mathrm{y}$ otros premios de instituciones varias) como para que los jurados y los premiables pasen a inscribirse en una suerte de banda de Moebius. Así puede darse que la admiración por un talento llegue a ser prepóstera (a la aparición del libro).

Todo parece indicar que ante los sordos imperativos de la crisis económica y los espesos nubarrones que se advierten desde el sótano provinciano, la más reciente poesía busca una escritura significativa apartándose tanto de la subordinación a las ideologías como de la trivialización del sentido. Ello independientemente de posturas y formas de ejercicio de la actividad poética. Claro está que quedan en pie cuestiones tales como cuánto se demora en ser joven, y fuera de anécdotas y finalidades, la más importante de cuales son sus relaciones y correspondencias con el mundo. No creo sea ésta la mejor ocasión para responder a dichas interrogantes. 
La generación del 45 activó hazañosamente un orden propio, el que, a falta de otra hipótesis más consistente, fue heredado tal cual por las generaciones siguientes. Su revisión de la generación del 900 fue ejemplar. Emir Rodríguez Monegal señala para su generación poética las fechas extremas de 1940 y 1965, y el inicio de una nueva poesía con la plurivocidad de Juan Cunha y la monocordia de Liber Falco (a quien creemos sobrestima en mucho como toda su posterioridad). No deja de ponderar al talento de Fernando Pereda(la consistencia de su obra aparece ahora gracias a una antología publicada recientemente). Las presencias reveladoras de Amanda Berenguer, Ida Vitale e Idea Vilarino son flanqueadas por Humberto Megget, Carlos Brandy y el prolífico Mario Benedetti (poesía de situación, dice Emir Rodríguez Monegal). Sarandy Cabrera (1923) ha conformado una obra densa no alejada del tono coloquial, francamente próxima a la prosa poética en equilibrio de humor y profusión de sensibilidad. Juan Cunha, aunque pertenece cronológicamente a esta generación, no coincide con sus posturas estéticas dominantes. Les acompañan Orfilia Bardesio y Ricardo Paseyro también nacidos como la mayor parte de esta generación entre 1920 y 1926. Algunos autores contemporáneos como Luis Bausero y Dora Isella Russel no han tenido eco alguno. ¿Se debería mencionar en este contexto a Rimoldi y a Picato? Cecilio Peña y Walter Ortiz y Ayala nacen en el 25 y el 29 pero, como Milton Schinca (29), empiezan a publicar muy tardíamente, lo que explica aparezcan citados en alguna bibliografía sobre la poesía de los 60 . ¿Cómo ubicar a Susana Soca, autora ella misma y mediadora incansable a través de la Revista Entregas de la Licorne con el viejo mundo y especialmente, París? (1)

Las revistas Número, Asir, Clinamen, Escritura y la imprenta La Galatea entre 1974 y 1955 son los principales vehículos de difusión grupal de la generación del 45. De la inmediata poesía de los años 20, —s decir de Sabat Ercasty, Emilio Oribe, Vicente Basso Maglio y Casaravilla Lemos para citar sus más nítidos valores- ${ }^{1}$ la generación del 45 recibe naturalmente el encauzamiento en las formas canónicas de la poesía castellana de gran equilibrio y buceo anímico, que va a trasvasar a odres nuevos, sin duda, un aprecio por la libertad formal que rechaza la imagen inintelegible (Parra del Riego). Luego harán propio un frecuente tono coloquial, al franco prosaismo de muchos y una autocritica feroz y a veces destructiva que se aplican sin compasión y transmiten a sus descendientes próximos.2

En la primera década del siglo se inaugura en Buenos Aires el trascendente período de vigencia del ultraísmo, con ámbitos estéticos muy precisos y un claro

\footnotetext{
${ }^{1}$ Sara de Ibáñez nace en la primera década del siglo (1903) y como asimismo Juana de Tbarbouru, que comienza a publicar en 1919 , son presencias desgajadas de grupos. Sus obras no dejan de exigir el mayor interés y una valoración impar.

2 Recuerdo una anécdota que ilustra la actitud frecuente en estos lares, de chiste arrasador: "¿Sabés lo que es un alfalfar? sic. preguntaba alguien $-\mathrm{y}$ contestaba ante la indecisión del interlocutor- un número doble de la Revista Alfar".
} 
despojamiento discursivo (recuérdese el interés manifestado por Borges por algunos poemas de Pedro Leandro Ipuche). En San Pablo el gran Oswald de Andrade y la Semana del 22 atacan el regionalismo y el realismo en una clara actitud transgresora que la generación del $\mathbf{4 5}$ se ingenia en ignorar. El Movimiento Antropófago deberá esperar otro barcoen Montevideo. La capacidad burlona del criollo, su ostensible pudor ante toda expresión extrema y su evidente contención del entusiasmo, juegan roles preponderantes para colorear esta producción con una paleta de tonos bajos, diría torresgarcianos. Sin embargo, se podría pensar que rescatan la utilización de la parodia y de la crítico-ironía creativa, así como ciertos "loci comuni" con la cosmópolis textualizada (Jorge Schwartz, 1989). La obra de Amanda Berenguer ha mantenido una actitud experimental digna de ser subrayada en su coherencia capaz de responder al llamado de una nueva sensibilidad. En Ida Vitale asistimos a la revelación de una poesía de la nitidez desafiante en su articulación de un lenguaje interiorizado y de la 'stasis', la fijeza (estrategia de fascinación y escritura conjetural).

La obra de idea Vilariño y su búsqueda de un trance ritual dionisíaco y de construcciones lapidarias de rara estabilidad formal, completa el tríptico de los poetas de mayor trascendencia de esta generación.

¿Cómo no rescatar en estas obras, en su rigor conceptual, en el uso de elementos de contención eimágenes espejeantes la influencia de María Eugenia Vaz Ferreira? ¿La marca asimétrica y la atmósfera translúcida de disparos y registros de Herreray Reissig? El juego de pesos y contrapesos entre vanguardia y modernismo, entre modernidad y tradición provoca en la poesía de estas voces extraordinarias del 45 la expresión de relaciones reverberantes entre el ojo y la lengua, el hallazgo de una sa(ra)zonada excentricidad.

Pueden señalarse otras notas, como una confianza total en la tarea intelectual; el cuño rebelde de corte individualista pero empeñado en liberarse de la autovaloración excesiva. Habitaron en un ámbito abigarrado de fusiones, y lo desmigajaron sin sentirlo como propio. Sus actitudes, muchas veces imbuidas del elemento circunstancial, son comprensibles por el eco de las guerras mundiales y esa constante apelación a la realidad del contexto como tarea de aprehensión previa a la especulación estética.

Entre los años 30 y 39 mientras desaparecían físicamente los últimos integrantes de la poesía de los 20, (sólo quedaban vivos Casaravilla Lemos y Basso Maglia) nacen algunos de los poetas cuya ascendencia inmediata como maestros y mentores de las promociones de los años 60 y 70 , va a resultar de decisivo empeño en una serie de rupturas, o microrupturas mejor, que van a ser operadas por sucesivas vivisecciones crítico-estéticas. Jorge Medina Vidal cuya actividad docente es de enorme gravitación en los poetas de los 70 y aún después. Washington Benavídez, en su búsqueda de una entonación vernácula y de acercamiento, como traductor, de distintas latitudes; Saúl Ibargoyen Islas, de incesante producción en tanto que autor y periodista, Circe Maia, Salvador Puig 
y Diego Pérez Pintos. Es difícil ubicar a Marosa di Giorgio en este contexto, por la índole de su obra y el momento en que comienza a publicarla (los tres autores citados publican a partir de 1963-65 sus primeros opus). También forman parte de esta promoción Rubén Yacovski, Ivan Kmaid, Gladys Castelvechi y Nancy Bacelo.

En la década del 40 nace una densa trama de poetas que de algún modo van a encarnar un cambio en el horizonte de expectativas alimentado por la recepción de obras y vanguardias que reclaman recipiente intramuros. Enrique Fierro, Roberto Echavarren, Cristina Peri Rossi, Jorge Arbeleche, Hugo Achugar, Alfredo Fressia, Tatiana Oroño, Clemente Padín, Juan Carlos Macedo. Alos dos primeros haré extensa referencia posteriormente y a los últimos mencionados espero poder hacerlo en la medida de haber comprendido su obra a la luz de la perspectiva elegida en este trabajo.

La escritura de Cristina Peri Rossi es la de una fragmentada espiral en la que un centro gravitacional orienta acumulaciones y visiones tan frescas como sutiles acerca de un orden de inmediata comprensión vital.

Jorge Arbeleche ha redactado una poesía de la contención y formas de inspiración canónica, buscando limpidez y la regularidad en el acento decantado.

Hugo Achugar a través de fracturas y una sintaxis elaborada ha aportado una escritura de registros múltiples en la que se insiste en una visión de Herrera y Reissig y una forma de cuestionar el texto y su contexto que ha encontrado eco en autores posteriores. Esto debe subrayarse como un efecto de bisagra y ampliarse a toda esta promoción. De sus maestros locales, con quienes mantuvieron un contacto inflamable y entrañable, debemos rescatar algunas notas y aportes críticos. El implacable cuestionamiento del instrumental, muchas veces en oposición a la búsqueda de una comunicación inmediata. La utilización de un referente subliminal y de un lenguaje interiorizado de reflexión crítica sobre sí mismo. El encuentro con nuevas formas tecnológicas. La fragmentación y dispersión del lenguaje y su riqueza tonal se vuelven casi innegables para quien haya seguido la evolución de la poesía en el Uruguay de las últimas décadas - entonces cristalizan tensiones y disyunciones que vinieron procesándose desde mucho antes pero no tan resueltamente-, que cualquier intento de explicación gradual de su desarrollo por estaciones y alineamientos sucesivos está condenado al fracaso. La madurez de una crítica del lenguaje poético, los ensayos de diversos vehículos de comunicación para el discurso poético (performances, video, art-mail, poesía visual) y la coexistencia de modalidades irreductibles, en paralelo inmixible, lo comprueban complementariamente. Estamos ante un laberinto poblado de retornos súbitos y aportes diferenciales; de eclipses y frases de transparencia. Haroldo de Campos ha denominado "constelaciones transtemporales" a los juegos de sincronías combinatorias asimiladoras de la diversidad de los tiempos de escrituras que deben ser rescatadas por una operación simultánea. Consignar denominadores generacionales o la existencia de grupos, si es que en 
determinadas promociones ello ocurió por consenso, o se expresaron en revistas como las mencionadas en la generación del 45 , sólo permite cumplir con la necesidad de amplios relevamientos de reconocimiento y articulación global. Los poemas plurales de Luis Campodónico, expresión viva de la utilización del plurilingüismo y los transcódigos, la feroz ironía de Medina Vidal, la austera armonía de Pereda, la versatilidad de conciencia de Cunha o el transubstancialismo de Marosa di Giorgio, no deben considerarse diacrónicamente sino como moradas enfrentadas del Logos poéticoen sincronía.

En un contexto en el que predominaron los miradores combatientes fundamentalistas por un lado, y por otro los poetas que cultivaron el lenguaje y sus recursos expansivos celebrandolos poderes de lainestabilidad, la conciencia crítica junto a la poesía del mensaje en varios tonos y registros, no podemos pensar que para los más recientes poetas se planteó la necesidad de dividir tierras y estéticas. Entre polos tan separados como amortiguados, claramente encarnados, más bien se vieron obligados a aceptar duras condiciones de transición hacia cuestiones de futuro. Las crudas ideas y, porqué no, la crueldad de las ideas acerca del discurso y su nexo con la realidad.

Eduardo Milán, distante de la mayoría, reside en una actitud predictiva y crítica. Entran asimismo en escena Guillermo Chaparro, Víctor Cunha, Juan María Fortunato, y posteriormente, otros jóvenes valores en los que aparece el diálogo con mecanismos de mutación del discurso poético y un alejamiento de las fobias de las vanguardias, Roberto Apratto, Marcelo Pareja, Elías Uriarte, Manuel García Rey y Alvaro Miranda.

Párrafo aparte merecenlas experiencias multimediales, el art-mail la poesía visual y el video. Clemente Padín, a pesar de la incomprensión general, activó desde fines de los sesenta, una secuencia de publicaciones, eventos y otras actividades de difusión, manteniendo contacto con el exterior. La revista Los Huevos del Plata (prólogo del № 1 de Medina Vidal) tuvo un rol muy señalado en tal sentido. Roberto Mascaró es autor de numerosas obras de video-poesía y performances. El Grupo de Uno reúne una serie de novísimos entre los que aparecen Héctor Bardanca, Gustavo Wojcochovsky, y Gustavo Escanlar caracterizado por una actitud irreverente y de experimentalismo que no excluye la actividad editorial. Gabriel Vieira pertenece a este grupo pero con una fuerza que lo distingue y aproxima a invenciones de lenguaje. Rafael Courtoisie, Raúl Castro Vega, Eduardo Espina (de vuelo expresivo) y Víctor Sosa son nombres que apuntan a la inscripción en un estrato reciente en el que habrá que estudiar la obra en progreso, así como los ultimísimos, Raúl Forlan Lamarque, Víctor Sosa, Alvaro Ojeda, Guillermo Baltar, Luis Bravo(responsable de performances en vivo), Marta Terra, Wellington Neira, Andrea Barbaranelli, Hugo Fontana, Ricardo Larrobla, Eduardo Paz, Ana Luisa Valdez, Alejandro Michelena, Eduardo Roland y Aldo Mazzuchelli.

Sin embargo este itinerar por una producción como la brevísimamente revistada nos permite distinguir la multiplicidad y riqueza de un panorama que 
seguirá requiriendo de inquisición y ejercicio de lecturas, aunque no debe separarnos de la consideración de aquellos que nos parecen especialmente relevantes para ilustrar registros de poeticidad (Nicolás Rosa) en la búsqueda de nuevos medios expresivos.

El sujeto en el discurso poético, ya desde Mallarmé se vuelve una autorreferencia a la posibilidad o la imposibilidad discursiva. Más que el juego no siempre efectuado entre tradición y ruptura nos parecen relevantes las lecturas que unos poetas hacen de otros y permanecen translucidasy perfumadas.

El mantenido empeño en revisar y replantear los postulados en los que reposa el texto poético, se advierte claramente en la obra de Jorge Medina Vida. La ironía de este agudo lector de Laforgue se refleja en fragmentos como el que sigue:

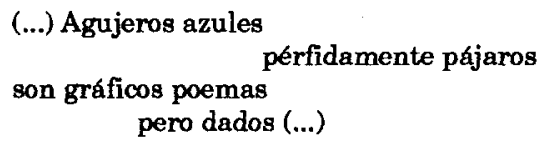

Homenaje, situación anómala (1977)

Nocreemos equivocarnos al relacionar su producción con el desdoblamiento crítico y la fusión del lenguaje coloquial y lenguaje hiperliterario en Alfredo Mario Ferreiro, quien, aunque de obra escasa y de desigual valor, es un raro cultivador del surrealismo intramuros. Veamos un fragmento de aquel libro que denominó Se ruega no dar la mano.

Por suerte se han acabado los versos. No hay más señores: los poetas ahora hacen poemas. Persiste, sin embargo la tendencia a dejar mucho papel en blanco ... (Ante todo)

O en "Las puertas" de Jorge Medina Vidal

\author{
No hablo ni escucho \\ como la dalia en el tintero \\ (Noche transfigurada)
}

En la obra de Enrique Fierro, la utilización significante del espacio blanco, la organización diacrónica estructural y la fragmentación sintáctica, reconducen al prisma crítico de los autores aludidos anteriormente.

Color casual

Thomas.

$$
\text { pero cielo de Dylan }
$$


tras una ventana)

o en:

¿El tropo "nubes"?

Pensar en las torres.

(De las claves de, Breve suma, 1966-1969)

La reflexión del texto sobre sí mismo y la sintaxis cuestionada, alcanzan en Eduardo Milán una concisión modélica, como lo ilustra este poema de la Plaqueta Eso es:

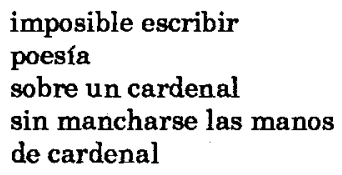

o el siguiente fragmento:

(página)
cuero
palabras

árido es

árido ahora donde el canto no-

(Estación/estaciones, 1975)

La yuxtaposición de oposiciones gráficas del significante, y la tensión rítmica del texto, progresan hasta llegar a un clima radical.

La realidad leída a través de una operación de descubrimiento del lenguaje rearma la experiencia de alusiones textuales, desconstruye un cierto orden en el que la poesía se refiere obligadamente a sí misma antes que a las cosas.

Así Roberto Appratto en Bien mirada (1977)

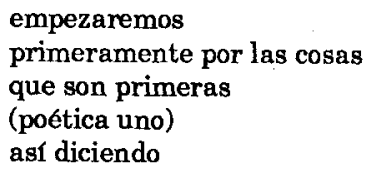


o Jorge Medina Vidal:

\author{
AHORA es el silencio \\ es la terraza \\ es la intemperie. \\ En el sillon te miro
}

(en Las terrazas, 1964)

el cuestionamiento del saber poético, traduce la confrontación de un exceso, de un desplazamiento de cierta novedad de lo discursivo o su interrupción, del sobrepasar los márgenes de autorreferencialidad del texto.

Las que podríamos denominar metáforas espaciales y el valor expresivo de los grafemas intencionales, (Constantin Crisan) tienen especial relieve en la escritura de Amanda Berenguer, más precisamente en la serie Los Ponientes', publicados en Composición de lugar (1976).

El uso del paisaje objetivado como en "la atónita desnudez de las cosas"... (Extasis) (vía el común P. Valéry) nos empujan a releer a Herrera y Reissig, y quizás a Ma . Eugenia Vaz Ferreira:

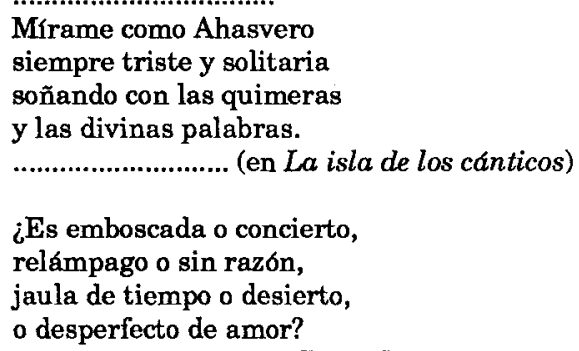

(A.B. en Contracanto, 1961)

Los efectos, las marcas que el lector encuentra, persistentes, nos desvian hacia otro espacio. Entonces volvemos a Alfredo Mario Ferreiro en Limpieza del camino aéreo:

Quién barre este camino? quién limpia el polvo de luz que se asentó sobre la carretera azul? 
o intentamos reverberar este fragmento en "Comunicaciones" de A. Berenguer:

Urge el pensamiento conectando ¿se siente? ¿alguien entre líneas? ¿errata? ¿parentesis? ¿qué signo? ¿escuchan?

La claridad del lenguaje

tiene apenas

la intensidad ambigua del poniente

(Quehaceres e invenciones, 1963)

Para comprender las variaciones de experimentación y práctica textual que suponen una actitud crítica, a veces más claramente expresada que en otras, pero prefiguradora de lo que vendrá a explayarse con perfil muy nítido en autores más jóvenes. ¿No son sus palabras en el verso: "otros cantan conmigo de memoria la luz que vendrá"? (Las nubes magallánicas, Materia Prima, 1960).

La obra de Marosa di Giorgio, constituye un verdadero "Black hole" en la poesía uruguaya. Quizá descubrimos resonancias de María Eugenia Vaz Ferreira en esta Obra-caracol, en espiral de intensidades que cristalizan en el disfrute de repeticiones hipnóticas. Remonta de fluencias del texto en mutaciones acumuladas; crispaciones amortiguadas del "sonido de una misma palabra" (Paternain) (1973). La simbología habla aquí (desde/sobre) el texto, soterrada, especularmente:

Quedé embelesada, aterrada. Era mi retrato remoto, el más antiguo, de la Creación y el principio del mundo.

Yo estaba ahí. (Mesa de Esmeralda, 1985)

Hay allí una prueba de ambigüedad y de 'nonsense', en espacios verbales intensamente metaforizantes en donde "lo mismo" re-presenta fantasmáticamente su desdoblamiento (naciendo) y desvaneciéndose ad infinitum.

Siguiendo el pensamiento de Gianni Vattimo en su interpretación de los cambios radicales que se verificaron en las últimas décadas, hemos comenzado a entender el significado de la experiencia estética como transformaciones, o instrumento de emancipación, no tanto como una capacidad de existencia utópica o reconciliada, sino como múltiples formas de existencias posibles, es decir, de heterotopías.

Actualmente puede decirse que algunos autores representan en la poesía platense este clivaje textual, heterotópico, ciertas estrategias micropolíticas. 
Enrique Fierro, Roberto Echavarren, Eduardo Milán, Di Giorgio, y más recientemente, Roberto Appratto y Javier Barreiro viajan a los fundadores. Nos ofrecen arrecifes volátiles. Efectos entre afectos. Una estrategia textural del texto poético.

Consideremos el siguiente fragmento de Imbuche de Echavarren:

No pudieron resistir, no pudieron mirar tu hermosura, tu comercio con el aire.

Narinas, boca, ano, sexo, oídos, ojos:

cosieron tus aberturas.

Monstruo de hermosura, cosido monstruo.

Cerraron orificios de tu piel, condenaron puertas de tu cuerpo

a ningún tráfico. Bola de carne

comerciaste sólo contigo en el misterio

del interior clausurado para siempre.

No te violaron. No te perdonaron.

Te veneran sin interrogarte.

Has dejado de torturarlos; te devolvieron la tortura puntada por puntada.

Ya no prometes nada a nadie.

(de Animalaccio, 1985)

Si todo este poema es crítico en cuanto a la verosimilitud de su yo-mítico, su capacidad de referencia ampliada y su pluri-estratificación lo vuelven metacrítico y de una materialidad porosa e irradiante. El texto se abre y se cierra sobre sí mismo por montajes entrópicos y esfumados retornos. Entre "diferencias de diferencias" (Derrida).

O también Eduardo Milán en:

Decir ahí es una flor difícil
decir ahí es pintar todo de pájaro
decir ahí es estar atrafdo
por la palabra áspera
cardo
y por el cardenal cardenal

(Nervaduras, 1985)

modela una escritura que se niega a representar un objeto exterior a ella misma que se constituye en su propio diagrama formal, en su propio dibujo. La discontinuidad rítmica provoca, diriamos, con rabia y avidez, la restitución de un discurso pleno. Los silencios son puntos cardinales en el huerto sellado del texto, en la transferencia de lecturas ideogramáticas. 
En el paisaje del Río de la Plata, una turbulencia de barro distrae la transparencia de la onda.

Si el gongorismo es de una cierta manera una huella estilística particularmente indeleble vía Lezama-Sarduy-Girondo-de Campos, en esta otra pluralidad de huellas a la que aludiéramos, reunida acrónicamente, y en sus cortes transversales, hay una apelación al lenguaje y la liberación del sentido que recaptura y le "da vuelta la pisada", a la práctica poética. Así los poetas desamortiguan la patria de la lengua (que es la única patria de los poetas) y transgerminan por estilos de estilos, en un espejo atonal, reverberante.

\section{BIBLIOGRAFIA}

Achugar, Hugo, Poesía y Sociedad. Montevideo, Arca, 1985.

Benedetti, Mario, Literatura uruguaya siglo XX. Montevideo: Alfa, 1963.

Bordolo, Domingo Luis, Antología de la poesía uruguaya contemporánea. Montevideo: Universidad de la República, 1966.

Fierro, Enrique, Antología de la poesía rebelde latinoamericana. Montevideo: Banda Oriental, 1967.

Paternain, Alejandro, 36 años de poesía uruguaya. Montevideo: Alfa, 1967.

Pedemonte, Hugo Emilio, Antología de la poesía viva latinoamericana. Barcelona: Seix Barral, 1966.

Rama, Ángel, 180 años de literatura. Montevideo: Enc. Urug., 1968.

Rama, Ángel, Testimonio, confesión y enjuiciamiento de 20 años de historia literaria y de nueva literatura uruguaya. Montevideo: Marcha, 3/julio/59. Real de Azúa, Carlos, Historia visible ehistoriaesotérica. Buenos Aires: Calicanto, 19.

Real de Azúa, Carlos, Un siglo y medio de cultura uruguaya. Montevideo: Universidad de la República, 1958.

Rodríguez Monegal, Emir, La nueva poesía uruguaya. Montevideo: Marcha 25/ agosto/1956, y 1/oct./54.

Rodríguez Monegal, Emir, Literatura uruguaya del Medio Siglo. Montevideo: Alfa, 1966. 
